IJEEM: Indonesian Journal of Environmental Education and Management, Volume 1 Nomor 1 Januari 2016

\title{
EVALUASI KEBIJAKAN PENGENDALIAN PENCEMARAN UDARA DALAM UPAYA MENINGKATKAN KUALITAS UDARA DKI JAKARTA
}

\section{Deshermansyah}

PT.Syah Perkasa Konsultan, Konsultan Industri dan Lingkungan, Boulevard Griya Permata C1/6 Cipondoh, Kota Tangerang 15147, Provinsi Banten ardeshhermansyah@yahoo.com

\begin{abstract}
This research aimed to evaluate the implementation of the Jakarta Regional Government Policy, Regional Regulation Number 2 of 2005 regarding Air Pollution Controlling is still valid. Evaluation results are expected to provide recommendations to the local government of Jakarta to repair/ improvement implementation, as well as making policy recommendations on control of air pollution that can be used as a reference for local governments and communities of Jakarta, and ensure the maintenance of wakefulness and air quality. This is a policy research study, the research design to follow the model of Haas \& Springer. Data collection activities carried out following the opinion Majchrzak and data analysis techniques using focused synthesis. From the research, suggests that the local government has not been able to implement the Jakarta DKI Jakarta Regional Regulation Number 2 of 2005 effectively and efficiently.
\end{abstract}

Keywords: evaluation policy, air pollution controlling, air quality

\section{Pendahuluan}

Udara memiliki fungsi yang sangat penting bagi kehidupan manusia dan makluk hidup lainnya. Sehingga udara merupakan sumber daya alam yang harus dilindungi untuk hidup dan kehidupan manusia juga makhluk hidup lainnya. Sebagai salah satu sumber daya alam yang sangat diperlukan bagi 
IJEEM: Indonesian Journal of Environmental Education and Management, Volume 1 Nomor 1 Januari 2016

kehidupan maka penurunan kualitas udara akan berpengaruh bagi kelangsungan hidup manusia serta makhluk hidup lainnya, sehingga mutu/kualitasnya harus selalu dijaga.Jumlah kendaraan bermotor di Jakarta demikian banyaknya dibandingkan dengan panjang jalan yang ada tidak akan mampu menampung kendaraan yang ada. Kondisi ini mengakibatkan kemacetan, ditambah lagi rendahnya tingkat disiplin pengguna jalan menjadikan kota Jakarta tiada hari tanpa macet. Kemacetan menyebabkan tingkat emisi semakin tinggi menjadikan udara semakin menurun kualitasnya.

Faktanya untuk saat ini pencemaran udara di Jakarta telah mencapai tingkat memprihatinkan sehingga menyebabkan turunnya kualitas udara sebagai sumber daya yang berkualitas. Penelitian yang dilakukan oleh Swiss Contact manyatakan bahwa udara Jakarta sudah tercemar dan $70 \%$ dari bahan pencemar dihasilkan oleh kendaraan bermotor, $90 \%$ oleh kendaraan pribadi (mobil).

Peraturan Daerah (Perda) Propinsi DKI Jakarta Nomor 2 Tahun 2005 tentang Pengendalian Pencemaran Udara, merupakan acuan dalam pengelolaan kualitas udara di Jakarta, sampai saat ini masih berlaku, ini perlu dievaluasi, bagaimanakah implementasinya.

Faktor penting untuk mendukung pelaksanaan pengendalian pencemaran udara ini dalah upaya pengawasan dan pemantauan terhadap kegiatankegiatan yang memiliki potensi mencemari udara. Pengawasan dilakukan 
IJEEM: Indonesian Journal of Environmental Education and Management, Volume 1 Nomor 1 Januari 2016

terhadap pentaatan peraturan-peraturan pengendalian pencemaran udara dan persyaratan yang tercantum dalam izin pembuangan limbah udara.

Komitmen pemerintah dan masyarakat Jakarta dalam upaya pengendalian pencemaran udara, sebagaimana tertuang dalam Perda Nomor 2 Tahun 2005, diwujudkan dengan mengimplementasikan empat hal pokok yang dititik beratkan untuk meminimasi bahan pencemar yaitu: 1) Kawasan tanpa rokok, 2) Uji emisi dan kebisingan, 3) Penggunaan bahan bakar gas, dan 4) Hari bebas kendaraan bermotor (HBKB).

Dalam perkembangan saat ini, implementasi empat hal pokok di atas merupakan bagian langkah strategis yang diperlukan untuk peningkatan kualitas lingkungan, meningkatnya derajat kesehatan masyarakat, juga berefek positif pada program diversifikasi energi. Pada sisi lingkungan, tingkat emisi gas buang relatif rendah berimplikasi meningkatkan kualitas lingkungan hidup, dalam konteks menurunnya sumber pencemar, pengaruhnya pada kesehatan manusia dapat dikontrol menurun, artinya sisi lingkungan menstimulasi peningkatan sisi kesehatan.

Apabila pengendalian mutu udara di Jakarta tidak dikelola dengan baik hal ini tentu saja akan berdampak buruk bagi kehidupan, karena perlindungan mutu udara untuk dapat mendukung kehidupan, mutlak diperlukan, bagi kelangsungan hidup manusia baik generasi sekarang maupun generasi mendatang. Perlindungan mutu udara, dimaksudkan untuk menjaga kualitas udara agar dalam tingkat yang aman bagi kehidupan, didasarkan pada baku mutu udara ambien dan status mutu udara ambien. 
IJEEM: Indonesian Journal of Environmental Education and Management, Volume 1 Nomor 1 Januari 2016

Berdasarkan uraian tersebut di atas, maka dipandang perlu untuk dilakukan penelitian terhadap implementasi dari Kebijakan Peraruran Daerah DKI Jakarta Nomor 2 Tahun 2005 tentang Pengendalian Pencemaran Udara.

Penelitian ini bertujuan untuk mengevaluasi implementasi dari Kebijakan Peraturan Daerah DKI Jakarta Nomor 2 Tahun 2005 tentang Pengendalian Pencemaran Udara demi terjaga dan terpeliharanya kualitas udara di Jakarta.

\section{METODE}

Penelitian ini dilakukan untuk mendapatkan informasi yang valid dan terpercaya mengenai implementasi sebuah kebijakan sehingga diperoleh informasi apakah pelaksanaannya telah sesuai dengan yang diharapkan. Sebagaimana dikemukakan oleh Dunn (1999: 9), bahwa evaluasi kebijakan dimaksudkan untuk mengetahui empat aspek, yaitu: 1) Proses pembuatan kebijakan, 2) Proses implementasi, 3) Konsekuensi kebijakan, dan (4) Efektivitas dampak kebijakan.

Dari penelitian yang dilakukan diperoleh hasil berupa pemaparan latar belakang permasalahan, kondisi permasalahan pada saat diselidiki, penyebab permasalahan, dan saran tindakan terhadap kebijakan Pemerintah Daerah DKI Jakarta.

Sebagai gambaran agar penelitian dapat dipahami secara jelas, dibuat kerangka penelitian, dapat dilihat pada gambar 1 berikut: 
IJEEM: Indonesian Journal of Environmental Education and Management, Volume 1 Nomor 1 Januari 2016

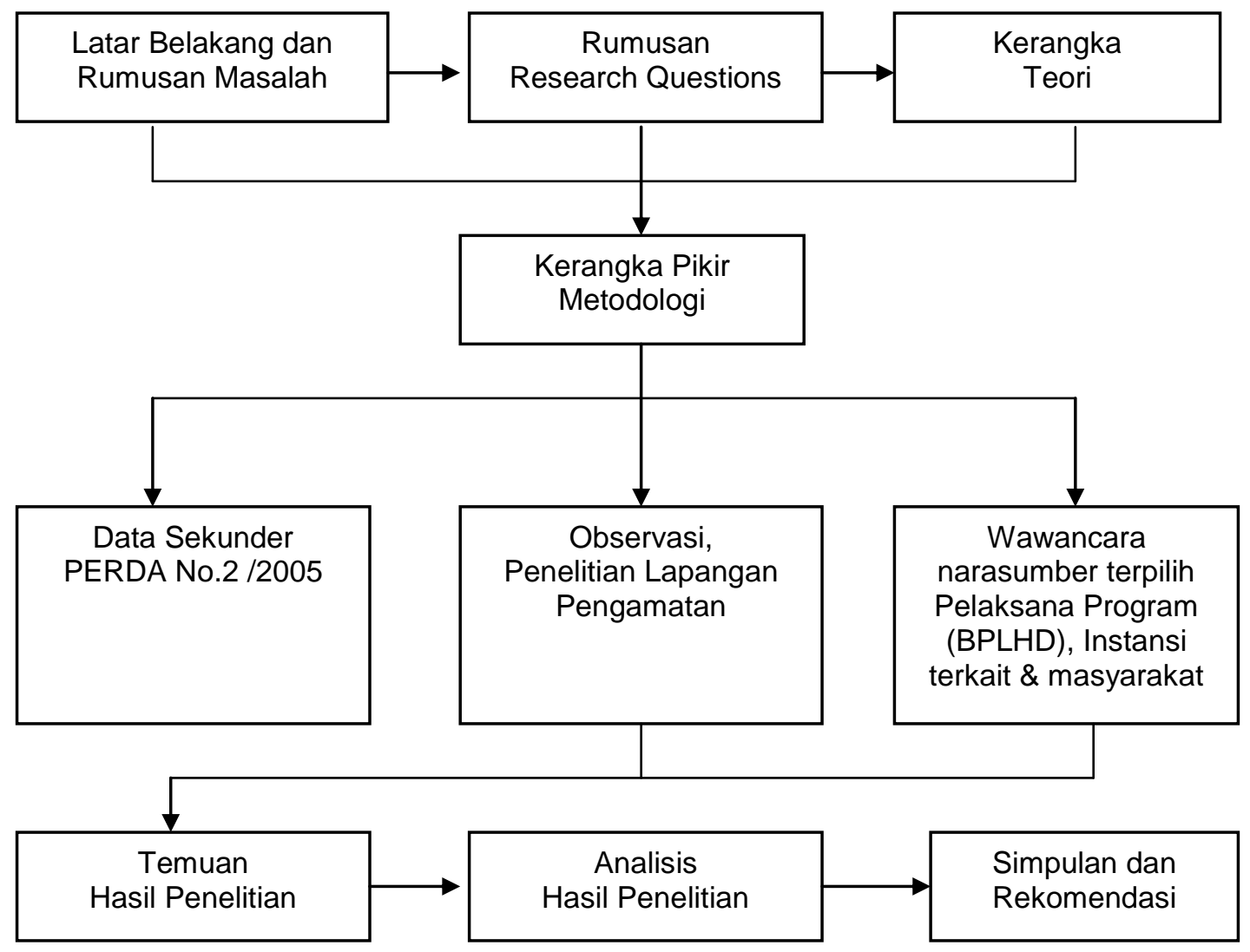

Gambar 1. Model Penelitian Kebijakan yang Dilaksanakan

Tahapan awal dalam penelitian melakukan pengamatan langsung di lapangan (observasi) dengan maksud untuk mengetahui bagaimana implementasi kebijakan sebenarnya di lapangan.

Desain model penelitian mengikuti pemikiran Haas dan Springer, pengumpulan data, dilakukan dengan lima aktifitas utama yakni: preparation, conceptualization, technichal analisys, recommendations analisys, and communications. Menurut Majchrzak, 1984 pengumpulan data di dalam penelitian kebijakan secara umum ditata secara berurutan: (1) Select social problem, (2) Identify key policy issues, (3) Trace progress of previous research and change efforts, (4) Obtain organizational charts of 
IJEEM: Indonesian Journal of Environmental Education and Management, Volume 1 Nomor 1 Januari 2016

decisionmaking bodies, (5) Draw model of policymaking process, (6) Interview stakeholders, and (7) Synthesize information. Selanjutnya untuk mengembangkan dan menyederhanakan pemikiran Majchrzak, disusun rancangan prosedur pengumpulan dan perekaman data untuk menjawab pertanyaan penelitian yang telah diajukan.

Untuk mendapatkan data tentang implementasi dan kinerja pengendalian pencemaran udara di DKI Jakarta, dilaksanakan observasi/survey terhadap masyarakat, difokuskan pada pelaksanaan pasal-pasal kebijakan Peraturan Daerah DKI Jakarta Nomor 2 Tahun 2005. Maksud dari observasi/survey, untuk mengumpulkan data primer yang dapat menjelaskan bagaimana pandangan masyarakat. Teknik pengumpulan data yang digunakan adalah wawancara kepada responden, merupakan pejabatpejabat sebagai pelaksana program di bidang pengendalian pencemaran udara.

Teknik analisis data yang digunakan dalam penelitian ini mengikuti pemikiran Majchrzak, dilakukan dengan analisis sintesis terfokus, yakni peneliti merumuskan terlebih dahulu pertanyaan penelitian (research questions), lalu melakukan sintesis terhadap informasi, yang berasal dari sumber data primer, sekunder, literatur, maupun riset terkait, dilengkapi dengan interview. Analisis sintesis terfokus dilakukan dengan cara interpretasi secara kritis oleh peneliti, apabila memungkinkan dibandingkan dengan kepustakaan yang relevan, dalam rangka menemukan kesamaan dan perbedaan dengan konsep-konsep yang ada. Dalam pelaksanaannya 
IJEEM: Indonesian Journal of Environmental Education and Management, Volume 1 Nomor 1 Januari 2016

setiap temuan dipertahankan dengan konsep atau teori yang berlaku dan dicari titik temu.

\section{HASIL}

1 Kebijakan Kawasan Dilarang Merokok

Tabel 1. Hasil Pemeriksaan Penerapan Kawasan Dilarang Merokok (KDM) oleh Instansi Pembina Tahun 2010 dan Hasil Penelitian Penulis Tahun 2012

\begin{tabular}{|c|c|c|c|c|}
\hline \multirow{2}{*}{ Kategori } & \multicolumn{2}{|c|}{ Data Sekunder } & \multicolumn{2}{c|}{ Data Primer } \\
\cline { 2 - 5 } & Jumlah & $\%$ & Jumlah & $\%$ \\
\hline Terbaik & 0 & 0 & 0 & 0 \\
\hline Sangat Baik & 9 & 9 & 9 & 9 \\
\hline Baik & 69 & 69 & 70 & 70 \\
\hline Cukup & 14 & 14 & 14 & 14 \\
\hline Buruk & 8 & 8 & 7 & 7 \\
\hline
\end{tabular}

Kriteria:

Nilai 100 : Terbaik (Penghargaan Internasional)

Nilai 81 - 100 : Sangat Baik (Penghargaan dari Bapak Gubernur Provinsi DKI Jakarta)

Nilai $61-80$ : Baik (Penghargaan dari Kepala Instansi Terkait)

Nilai $51-60$ : Cukup (Pembinaan dari Kepala Instansi Terkait)

Nilai 0 - 50 : Buruk (Teguran dari Kepala Instansi Terkait)

\section{Boks 1:}

Evaluasi impelementasi Kebijakan Kawasan Dilarang Merokok yang diterapkan oleh Pemerintah Daerah DKI Jakarta seperti yang tercantum pada Kebijakan Peraturan Daerah DKI Jakarta Nomor 2 Tahun 2005 dan bila dilihat berdasarkan Tabel 1 di atas terlihat bahwa $\pm 70 \%$ sudah diimplementasikan dengan "Baik" 
IJEEM: Indonesian Journal of Environmental Education and Management, Volume 1 Nomor 1 Januari 2016

2. Kebijakan Uji Emisi dan Kebisingan

Tabel 2. Uji Emisi Hasil Pelaksanaan Uji Emisi Kendaraan Tahun 20052012

\begin{tabular}{|c|c|c|c|c|c|c|}
\hline \multirow{2}{*}{ No } & \multirow{2}{*}{ Tahun } & \multirow{2}{*}{$\begin{array}{l}\text { Jumlah } \\
\text { Kendaraan }\end{array}$} & \multicolumn{4}{|c|}{ Hasil } \\
\hline & & & Lulus & $\%$ & $\begin{array}{l}\text { Tidak } \\
\text { Lulus }\end{array}$ & $\%$ \\
\hline 1 & 2005 & 19.538 & 14.753 & $76 \%$ & 4.785 & $24 \%$ \\
\hline 2 & 2006 & 27.665 & 24.830 & $90 \%$ & 2.835 & $10 \%$ \\
\hline 3 & 2007 & 15.918 & 9.751 & $61 \%$ & 6.167 & $39 \%$ \\
\hline 4 & 2008 & 30.443 & 26.296 & $86 \%$ & 4.147 & $14 \%$ \\
\hline 5 & 2009 & 21.931 & 20.832 & $95 \%$ & 1.099 & $5 \%$ \\
\hline 6 & 2010 & 19.856 & 19.214 & $97 \%$ & 642 & $3 \%$ \\
\hline 7 & 2011 & 15.432 & 12.961 & $84 \%$ & 2.471 & $16 \%$ \\
\hline 8 & 2012 & 11.658 & 9.760 & $84 \%$ & 1.898 & $16 \%$ \\
\hline & $\overline{J M L A H}$ & 162.441 & 138.397 & $85 \%$ & 24.044 & $15 \%$ \\
\hline
\end{tabular}

Sumber: BPLHD DKI Jakarta, 2012

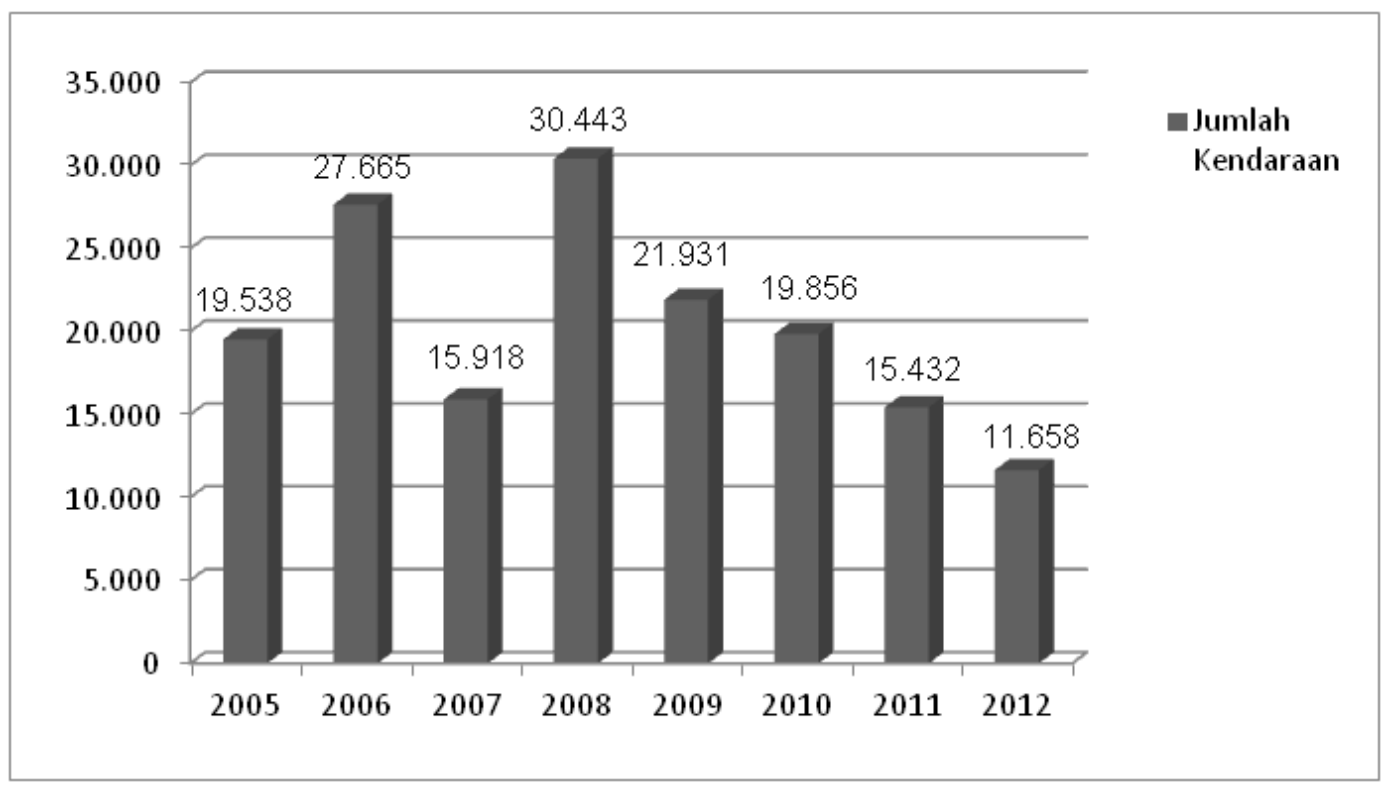

Gambar 1. Grafik Jumlah Kendaraan yang Melakukan Uji Emisi Tahun $2005-2012$ 
IJEEM: Indonesian Journal of Environmental Education and Management, Volume 1 Nomor 1 Januari 2016

Berdasarkan tabel di atas, didapatkan bahwa pelaksanaan uji emisi kendaraan bermotor pada kawasan tertentu tahun 2012 sebagai berikut: (1) Pelaksanaan uji emisi pada kawasan tertentu pada 37 lokasi, sebanyak 11658 kendaraan, kendaraan yang lulus uji emisi 9760 kendaraan (84\%) dan tidak lulus 1898 kendaraan (16\%), (2) Kendaraan melakukan uji emisi berbahan bakar bensin 8458 kendaraan (73\%), dan bahan bakar solar 3200 kendaraan (27\%), (3) Pelaksanaan uji emisi kendaraan bermotor oleh 16 instansi pemerintah, 1 perguruan tinggi, 1 kawasan industri, dan 19 kegiatan usaha, (4) Pelaksanaan uji emisi di kawasan terbatas dilakukan oleh bengkel pelaksana uji emisi yaitu Bengkel Dwi Arga, Bengkel Auto 2000 (Saharjo), Bengkel Honda Megatama Mandiri, dan Bengkel Tunas Toyota Bintaro, (5) Bagi kendaraan yang tidak lulus uji emisi disarankan untuk melakukan perawatan kendaraan secara rutin.

\section{Boks 2:}

Evaluasi impelementasi kebijakan Uji Emisi dan Kebisingan seperti yang tercantum pada Kebijakan Peratuan Daerah DKI Jakarta Nomor 2 Tahun 2005 "sudah diimplementasikan" oleh Badan Pengelola Lingkungan Hidup Daerah Provinsi DKI Jakarta, tapi kecenderungannya bila dilihat dari Tabel 2 di atas jumlah kendaraan yang melakukan uji emisi dan kebisingan 4 (empat) tahun terakhir cendrung menurun, hal ini dikarenakan, belum diterapkannya uji emisi dan kebisingan oleh Kantor Samsat (tempat pembayaran pajak kendaraan bermotor) di DKI Jakarta sebagai persyaratan untuk memperpanjang pembayaran pajak kendaraan bermotor setiap tahunnya di DKI Jakarta. 
IJEEM: Indonesian Journal of Environmental Education and Management, Volume 1 Nomor 1 Januari 2016

\section{Kebijakan Penggunaan Bahan Bakar Gas}

Tabel 3. Penerapan Bahan Bakar Gas di Wilayah DKI Jakarta

\begin{tabular}{|c|c|c|c|c|}
\hline No. & Keqiatan & 2010 & 2011 & 2012 \\
\hline 1 & $\begin{array}{l}\text { Supply: } \\
\text { - Penambahan } \\
\text { SPBG } \\
\text { - Perluasan } \\
\text { Jaringan } \\
\text { Pipa Gas }\end{array}$ & $\begin{array}{l}\text { - Pengembangan } \\
\text { konsep Mother } \\
\text { Daughter System } \\
\text { - Revitalisasi } \\
\text { SPBG berbasis } \\
\text { CNG }\end{array}$ & $\begin{array}{l}\text { - Kemudahan } \\
\text { perizinan bagi } \\
\text { swasta untuk } \\
\text { berinvestasi } \\
\text { - Pengembangan } \\
\text { LGV } \\
\text { - Melepas harga } \\
\text { sesuai harga } \\
\text { perekonomian }\end{array}$ & $\begin{array}{l}\text { - Dukungan } \\
\text { Mother } \\
\text { Daughter } \\
\text { System }\end{array}$ \\
\hline 2 & $\begin{array}{l}\text { Safety: } \\
\text { - Sertifikasi } \\
\text { Bengkel } \\
\text { - Sertifikasi } \\
\text { Teknisi }\end{array}$ & $\begin{array}{l}\text { - Dibentuk badan } \\
\text { sertifikasi bengkel } \\
\text { Dishub \& Dephub } \\
\text { - Training pelatihan } \\
\text { instalator BBG } \\
\text { besertifikat } \\
\text { - Pengawasan }\end{array}$ & $\begin{array}{l}\text { - Training/pelatihan } \\
\text { instalator BBG } \\
\text { besertifikat } \\
\text { - Pengawasan }\end{array}$ & $\begin{array}{l}\text { - Training/ } \\
\text { pelatihan } \\
\text { instalator BBG } \\
\text { besertifikat } \\
\text { - Pengawasan }\end{array}$ \\
\hline 3 & $\begin{array}{l}\text { Sosialisasi: } \\
\text { - Edukasi } \\
\text { Penerapan } \\
\text { BBG }\end{array}$ & $\begin{array}{l}\text { - Temu Pengusaha } \\
\text { difasilitasi oleh } \\
\text { organda } \\
\text { - Media cetak dan } \\
\text { elektronik (edukasi } \\
\text { masyarakat seperti } \\
\text { halnya program } \\
\text { konversi minyak } \\
\text { tanah) }\end{array}$ & $\begin{array}{l}\text { - Temu pengusaha } \\
\text { difasilitasi oleh } \\
\text { organda } \\
\text { - Media cetak dan } \\
\text { elektronik (eduka- } \\
\text { si masyarakat } \\
\text { seperti halnya } \\
\text { program } \\
\text { konversi minyak } \\
\text { tanah }\end{array}$ & $\begin{array}{l}\text { - Temu } \\
\text { pengusaha } \\
\text { difasilitasi oleh } \\
\text { organda } \\
\text { - Media cetak dan } \\
\text { Elektronik (edu- } \\
\text { kasi masyarakat } \\
\text { seperti halnya } \\
\text { program konver- } \\
\text { si minyak tanah) }\end{array}$ \\
\hline 4 & $\begin{array}{l}\text { Demand: } \\
\text { - Penerapan } \\
\text { BBG untuk } \\
\text { Kendaraan } \\
\text { Organisasi } \\
\text { Pemda }\end{array}$ & $\begin{array}{l}\text { - Pembuatan fasili- } \\
\text { tas BBG di kantor } \\
\text { gubernur,walikota } \\
\text { - Seluruh kendaraan } \\
\text { dinas dikonversi }\end{array}$ & $\begin{array}{l}\text { - Pembuatan fasili- } \\
\text { tas BBG di kantor } \\
\text { gubernur,walikota } \\
\text { - Seluruh } \\
\text { kendaraan dinas } \\
\text { dikonversi }\end{array}$ & $\begin{array}{l}\text { - Pembuatan fasi- } \\
\text { litas BBG di } \\
\text { kantor gubernur, } \\
\text { walikota } \\
\text { - Seluruh kenda- } \\
\text { raan dinas } \\
\text { dikonversi }\end{array}$ \\
\hline 5 & $\begin{array}{l}\text { Demand: } \\
\text { - Penerapan } \\
\text { BBG untuk } \\
\text { Angkutan } \\
\text { Umum }\end{array}$ & $\begin{array}{l}\text { - Monitoring perpan- } \\
\text { jangan izin trayek } \\
\text { - Peremajaan wajib } \\
\text { menggunakan gas }\end{array}$ & $\begin{array}{l}\text { - Monitoring per- } \\
\text { panjangan izin } \\
\text { trayek } \\
\text { - Peremajaan wajib } \\
\text { menggunakan } \\
\text { gas }\end{array}$ & $\begin{array}{l}\text { - Monitoring per- } \\
\text { panjangan izin } \\
\text { trayek } \\
\text { - Peremajaan } \\
\text { wajib menggu- } \\
\text { nakan gas }\end{array}$ \\
\hline 6 & $\begin{array}{l}\text { Dishub, DLLAJ } \\
\text { dan Dephub }\end{array}$ & $\begin{array}{l}\text { Monitoring } \\
\text { kendaraan yang } \\
\text { sudah dikonversi } \\
\text { menggunakan } \\
\text { database dan RFIQ }\end{array}$ & $\begin{array}{l}\text { Monitoring } \\
\text { kendaraan yang } \\
\text { sudah dikonversi } \\
\text { menggunakan } \\
\text { database dan RFIQ }\end{array}$ & $\begin{array}{l}\text { Monitoring } \\
\text { kendaraan yang } \\
\text { sudah dikonversi } \\
\text { menggunakan } \\
\text { database dan } \\
\text { RFIQ }\end{array}$ \\
\hline 7 & $\begin{array}{l}\text { Koordinasi } \\
\text { Stakeholder }\end{array}$ & $\begin{array}{l}\text { Komitmen } \\
\text { pelaksanaan }\end{array}$ & $\begin{array}{l}\text { Komitmen } \\
\text { pelaksanaan }\end{array}$ & $\begin{array}{l}\text { Komitmen } \\
\text { pelaksanaan }\end{array}$ \\
\hline
\end{tabular}

Sumber BPLHD DKI Jakarta, 2012 
IJEEM: Indonesian Journal of Environmental Education and Management, Volume 1 Nomor 1 Januari 2016

Dari pengamatan Badan Pengelola Lingkungan Hidup Daerah Provinsi DKI Jakarta 2010, dan pengamatan peneliti tahun 2012 populasi kendaraan yang menggunakan bahan bakar gas dapat dikelompokkan pada beberapa kategori:

Tabel 4. Angkutan Umum dan Kendaraan Pemda yang menggunakan Bahan Bakar Gas

\begin{tabular}{|c|c|c|c|c|}
\hline \multirow{2}{*}{ Kategori } & \multicolumn{2}{|c|}{ Data Sekunder } & \multicolumn{2}{c|}{ Data Primer } \\
\cline { 2 - 5 } & Jumlah & $\%$ & Jumlah & $\%$ \\
\hline A. Angkutan Umum & & & & \\
\hline $\begin{array}{c}\text { 1. Bus Besar } \\
\text { (Non Busway) }\end{array}$ & 0 & 0 & 0 & 0 \\
\hline 2. Busway & 317 & 74,41 & 317 & 100 \\
\hline 3. Mikrolet & 36 & 0,53 & 0 & 0 \\
\hline 4. Taksi & 1755 & 7,22 & 878 & 3,6 \\
\hline 5. Bajai & 755 & 5,23 & 378 & 2,6 \\
\hline $\begin{array}{c}\text { B. Kendaraan } \\
\text { Operasional Pemda }\end{array}$ & 0 & 0 & 0 & 0 \\
\hline
\end{tabular}

\section{Boks 3:}

- Evaluasi impelementasi Kebijakan Penggunaan Bahan Bakar Gas untuk angkutan umum dan kendaraan opersional Pemerintah Daerah seperti yang tercantum pada Kebijakan Peraturan Daerah DKI Jakarta Nomor 2 Tahun 2005 seperti terlihat pada Tabel 4 "belum diimplementasikan" dengan benar.

- Dari Tabel 4 terlihat hanya busway saja yang menggunakan bahan bakar gas dan sebagian kecil saja taksi dan bajai menggunakan bahan bakar gas, serta tak satu pun kendaraan operasional Pemerintah Daerah DKI Jakarta yang menggunakan bahan bakar gas.

- Kebijakan ini belum diimplementasikan dengan benar dikarenakan hal ini tidak terlepaskan dari berbagai kesiapan teknis yang ada. faktor teknis disini merupakan kombinasi antara aspek supply, aspek demand, aspek safety dan aspek economy. 
IJEEM: Indonesian Journal of Environmental Education and Management, Volume 1 Nomor 1 Januari 2016

4. Kebijakan Hari Bebas Kendaraan Bermotor

Tabel 5. Pelaksanaan Hari Bebas Kendaraan Bermotor

\begin{tabular}{|c|c|}
\hline Tahun & Pelaksanaan Program \\
\hline 2007 & $\begin{array}{l}\text { 1. Launching HBKB oleh Gubernur Provinsi DKI Jakarta } \\
\text { 2. Pelaksanaan HBKB Jl. Sudirman - JI. Thamrin dan } \\
\text { kawasan Kota Tua, tiga kali dalam setahun }\end{array}$ \\
\hline 2008 & $\begin{array}{l}\text { 1. Peningkatan pelaksanaan HBKB Jl. Sudirman - } \\
\text { Jl. Thamrin, satu kali dalam sebulan } \\
\text { 2. Peningkatan lokasi pelaksanaan HBKB di lima wilayah, } \\
\text { satu kali dalam setahun }\end{array}$ \\
\hline 2009 & $\begin{array}{l}\text { 1. Melanjutkan pelaksanaan HBKB Jl. Sudirman - } \\
\text { Jl. Thamrin, satu kali dalam sebulan } \\
\text { 2. Peningkatan pelaksanaan HBKB di lima wilayah, dua } \\
\text { kali dalam setahun } \\
\text { 3. Peningkatan pelaksanaan HBKB Jl. Sudirman - } \\
\text { Jl. Thamrin, dua kali dalam sebulan } \\
\text { 4. Melanjutkan pelaksanaan HBKB di lima wilayah, dua } \\
\text { kali dalam setahun }\end{array}$ \\
\hline 2010 & $\begin{array}{l}\text { 1. Peningkatan pelaksanaan HBKB Jl. Sudirman - } \\
\text { Jl. Thamrin, dua kali dalam sebulan } \\
\text { 2. Melanjutkan pelaksanaan HBKB di lima wilayah, dua } \\
\text { kali dalam setahun }\end{array}$ \\
\hline 2011 & $\begin{array}{l}\text { 1. Melanjutkan pelaksanaan HBKB Jl. Sudirman - } \\
\text { Jl. Thamrin, dua kali dalam sebulan } \\
\text { 2. Melanjutkan pelaksanaan HBKB di lima wilayah, dua } \\
\text { kali dalam setahun }\end{array}$ \\
\hline 2012 & $\begin{array}{l}\text { 1. Meningkatkan pelaksanaan HBKB JI. Sudirman - } \\
\text { Jl. Thamrin, satu kali dalam Seminggu sesuai Instruksi } \\
\text { Gubernur No. } 78 \text { Tahun } 2011 \\
\text { 2. Melanjutkan pelaksanaan HBKB di lima wilayah, satu } \\
\text { kali dalam sebulan sesuai Instruksi Gubernur No. } 78 \\
\text { Tahun } 2011\end{array}$ \\
\hline
\end{tabular}

Sumber BPLHD DKI Jakarta, 2012 
IJEEM: Indonesian Journal of Environmental Education and Management, Volume 1 Nomor 1 Januari 2016

\section{Boks 4:}

Evaluasi impelementasi Kebijakan Hari Bebas Kendaraan Bermotor (HBKB) seperti yang tercantum pada Kebijakan Peraturan Daerah DKI Jakarta Nomor 2 Tahun 2005 dan seperti terlihat pada Tabel 5 menunjukkan bahwa program ini sudah diimplementasikan, adanya peningkatan pelaksanaan HBKB JI.Sudirman - Jl. Thamrin semula hanya tiga kali dalam setahun menjadi satu kali dalam seminggu, dan pelaksanaan HBKB di lima wilayah DKI Jakarta, semula hanya satu kali dalam setahun menjadi satu kali dalam sebulan.

\section{PEMBAHASAN}

Dalam konteks pengendalian pencemaran udara, evaluasi terhadap implementasi peraturan perundang-undangan dan perizinan lingkungan bertujuan, mengetahui akurasi tingkat efektivitas dan efisiensi instrumen hukum pengelolaan kualitas udara. Evaluasi penerapan peraturan perundangan dan perizinan lingkungan bidang pengendalian pencemaran udara pada hakekatnya berkaitan dengan persoalan fakta dan logika yuridis. Upaya pengendalian pencemaran udara dengan Perda Nomor 2 Tahun 2005 terdapat beberapa kebijakan pokok lebih dititik beratkan meminimasi bahan pencemar yaitu: 1) Kebijakan Kawasan Tanpa Rokok, 2) Kebijakan Uji Emisi dan Kebisingan, 3). Kebijakan Penggunaan Bahan Bakar Gas untuk kendaraan umum dan mobil operasional Pemerintah Daerah DKI JAKARTA, dan 4) Kebijakan Hari Bebas Kendaraan Bermotor (HBKB). 
IJEEM: Indonesian Journal of Environmental Education and Management, Volume 1 Nomor 1 Januari 2016

Upaya pengendalian pencemaran udara yang pertama adalah Kebijakan Kawasan Tanpa Rokok. Evaluasi impelementasi kebijakan ini $\pm 70 \%$ sudah diimplementasikan dengan baik.

Peraturan Daerah DKI Jakarta Nomor 2 Tahun 2005, pasal 13 ayat (1) dinyatakan, tempat umum, sarana kesehatan, tempat kerja dan tempat yang secara spesifik sebagai tempat proses belajar mengajar, area kegiatan anak, tempat ibadah dan angkutan umum dinyatakan sebagai kawasan dilarang merokok.

Kebijakan Kawasan Tanpa Rokok dicanangkan oleh Pemerintah Daerah DKI Jakarta merupakan upaya perlindungan untuk masyarakat Jakarta terhadap resiko ancaman gangguan kesehatan karena lingkungan tercemar asap rokok, yaitu penyediaan ruangan atau area yang dinyatakan dilarang untuk kegiatan merokok atau memproduksi, menjual, mengiklankan, dan/atau mempromosikan produk tembakau. Sedangkan tempat khusus untuk merokok adalah ruangan diperuntukkan khusus untuk kegiatan merokok, berada di dalam kawasan tanpa rokok (KTR).

Masih adanya beberapa masyarakat Jakarta memiliki kesadaran yang rendah tentang bahaya merokok, menjadi alasan sulitnya kebijakan penetapan kawasan tanpa rokok di tempat-tempat dilarang merokok berjalan 100\%. Penetapan kawasan tanpa rokok di DKI Jakarta telah banyak diupayakan berbagai pihak, namun kenyataannya upaya yang dilakukan tersebut jauh tertinggal dibandingkan dengan penjualan, periklanan/promosi penggunaan rokok. 
IJEEM: Indonesian Journal of Environmental Education and Management, Volume 1 Nomor 1 Januari 2016

Upaya pengendalian pencemaran udara yang ke dua adalah kebijakan Uji Emisi dan Kebisingan. Dalam Peraturan Daerah DKI Jakarta Nomor 2 Tahun 2005, pasal 19 dinyatakan: (1) Kendaraan bermotor wajib memenuhi ambang batas emisi gas buang kendaraan bermotor, (2) Kendaraan bermotor sebagaimana dimaksud, wajib menjalani uji emisi sekurangkurangnya setiap enam bulan, (3) Bagi kendaraan bermotor yang dinyatakan lulus uji emisi diberi tanda lulus uji emisi, (4) Uji emisi dapat dilakukan oleh instansi yang bertanggung jawab dibidang lalu lintas dan angkutan jalan dan/atau pihak swasta yang memiliki bengkel umum yang telah memenuhi syarat, (5) Hasil uji emisi kendaraan bermotor merupakan bagian dari persyaratan pembayaran pajak kendaraan bermotor Evaluasi impelementasi kebijakan Uji Emisi dan Kebisingan "sudah diimplementasikan" oleh Badan Pengelola Lingkungan Hidup Daerah DKI Jakarta, tapi kecendrungannya bila dilihat dari jumlah kendaraan yang melakukan uji emisi dan kebisingan, 4 (empat) tahun terakhir cenderung menurun, dikarenakan Kantor Samsat (tempat pembayaran pajak kendaraan bermotor) di DKI Jakarta, belum mewajibkan kendaraan bermotor menjalani uji emisi sekurang-kurangnya setiap enam bulan dan belum diterapkannya uji emisi dan kebisingan sebagai persyaratan untuk memperpanjang pembayaran pajak kendaraan bermotor setiap tahunnya.

Program rewards and punishment dapat dijadikan alat kontrol bagi pemilik kendaraan, yang akan memperpanjang Surat Tanda Nomor Kendaraan 
IJEEM: Indonesian Journal of Environmental Education and Management, Volume 1 Nomor 1 Januari 2016

(STNK) kendaraannnya, dan ini harus diberlakukan kembali oleh Pemerintah Daerah DKI Jakarta.

Upaya pengendalian pencemaran udara yang ke tiga adalah kebijakan Penggunaan Bahan Bakar Gas (BBG), kebijakan ini belum diimplementasikan dengan benar. Apapun dan bagaimanapun kondisi terkini dari pemanfaatan BBG untuk sektor transportasi di DKI Jakarta, tidak terlepas dari berbagai kesiapan teknis. Faktor teknis adalah kombinasi antara aspek supply (ketersediaan gas dan peralatan teknis kendaraan BBG terkait), aspek demand (kesiapan kendaraan BBG dan fasilitas terkaitnya), asfek safety (tingkat keamanan penggunaan kendaraan dan fasilitas BBG lainnya) dan aspek economy (perhitungan ekonomi dan berbagai insentif yang dapat dipergunakan). Bila keempat aspek faktor teknis tersebut telah terprogramkan dan tersedia sedemikian rupa pada kondisi yang relatif cukup, maka implementasi penggunaan BBG, baik untuk kendaraan operasional pemda maupun angkutan umum dapat difokuskan dengan target utama meningkatkan penggunaan kendaraan berbahan bakar gas secara optimal.

Kendaraan operasional Pemerintah Daerah Jakarta tidak ada yang menggunakan bahan bakar gas. Pasalnya, saat ini bahan bakar gas penggunaannya belum memasyarakat dan penggunaan bahan bakar gas terbatas pada sebagian kendaraan umum seperti bajai dan busway. Jumlah pemakaian bahan bakar gas masih sangat kecil. Jika bahan bakar gas adalah cara yang dipilih untuk mengurangi emisi, maka seharusnya 
IJEEM: Indonesian Journal of Environmental Education and Management, Volume 1 Nomor 1 Januari 2016

pemerintah berinvestasi lebih pada sektor gas dengan mendirikan stasiun Pengisian Bahan Bakar Gas (SPBG).

Jenis bahan bakar kendaraan bermotor yang umum digunakan di DKI Jakarta adalah premium dan solar. Ketersediaan bensin tanpa $\mathrm{Pb}$ (unleaded gasoline) dan minyak solar dengan kandungan belerang rendah merupakan faktor kunci dalam penurunan emisi kendaraan, karena bahan bakar jenis tersebut dapat digunakan oleh kendaraan bermotor dengan teknologi mutahir yang mampu mengurangi emisi kendaraan secara signifikan.

Mencermati situasi terkini dimana pada kenyataannya implementasi pengunaan bahan bakar gas pada kendaraan bermotor di Jakarta dihadang berbagai persoalan pada faktor-faktor aspek teknis, maka kegiatan sosialisasi tetap dipandang perlu untuk terus dilakukan. Dalam kondisi belum optimalnya implementasi maka sasaran utama sosialisasi diarahkan pada peningkatan pemahaman akan arti pentingnya program penggunaan bahan bakar gas untuk kendaraan di Jakarta dan penyatuan persepsi antar instansi dan unsur-unsur stakeholder terkait.

Upaya pengendalian pencemaran udara yang ke empat adalah, kebijakan Hari Bebas Kendaraan Bermotor (HBKB), evaluasi impelementasi kebijakan HBKB seperti tercantum pada Kebijakan Peraturan Daerah DKI Jakarta Nomor 2 Tahun 2005 menunjukkan kebijakan ini sudah diimplementasikan, adanya peningkatan pelaksanaan HBKB Jl.Sudirman - Jl. Thamrin semula hanya tiga kali dalam setahun menjadi satu kali dalam seminggu, dan pelaksanaan HBKB di lima wilayah DKI Jakarta, semula hanya satu kali 
IJEEM: Indonesian Journal of Environmental Education and Management, Volume 1 Nomor 1 Januari 2016

dalam setahun menjadi satu kali dalam sebulan, program ini sampai saat ini telah berjalan dengan baik.

Peraturan Daerah DKI Jakarta Nomor 2 Tahun 2005, pasal 27 dinyatakan:

(1) Dalam rangka pemulihan mutu udara ditetapkan hari bebas kendaraan bermotor pada kawasan tertentu, (2) Hari bebas kendaraan bermotor pada kawasan tertentu sekurang-kurangnya 1 (satu) kali dalam 1 (satu) bulan.

Pelakasanaan HBKB pertama kali di INDONESIA yaitu di DKI Jakarta diselenggarakan sejak 27 April 2008. HBKB di Jakarta dilaksanakan pada minggu ke 4 setiap bulanya, dan larangan melintas bagi kendaraan bermotor dimulai dari jam 6 pagi hingga jam 12 siang.

Hari Bebas Kendaraan Bermotor (HBKB) atau lebih dikenal dengan Car Free Day (CFD), merupakan suatu program yang diterapkan oleh Pemerintah Daerah DKI Jakarta untuk memberikan kesempatan bagi warga Jakarta menikmati udara segar di akhir pekan tanpa adanya gangguan polusi dari kendaraan bermotor, kegiatan ini diselenggarakan tiap hari minggu secara bergantian di seluruh wilayah administrasi Jakarta. Di Jakarta HBKB akan rutin dilakukan setiap hari minggu, karena dampak positif dari kebijakan ini sudah dirasakan oleh penduduk Jakarta.

\section{KESIMPULAN DAN REKOMENDASI}

Berdasarkan penelitian yang dilakukan yaitu mengevaluasi Kebijakan Peraturan Daerah Nomor 2 Tahun 2005 tentang Pengendalian Pencemaran Udara, dapat disimpulkan: Pertama, impelementasi kebijakan Kawasan Dilarang Merokok yang diterapkan oleh Pemerintah Daerah DKI Jakarta, \pm 
IJEEM: Indonesian Journal of Environmental Education and Management, Volume 1 Nomor 1 Januari 2016

70\% sudah diimplementasikan dengan "Baik", Kedua, impelementasi kebijakan Uji Emisi dan Kebisingan "sudah diimplementasikan", tapi kecendrungannya bila dilihat dari Jumlah kendaraan yang melakukan uji emisi dan kebisingan 4 (empat) tahun terakhir cenderung menurun. Ketiga, impelementasi kebijakan Penggunaan Bahan Bakar Gas untuk angkutan umum dan kendaraan opersional Pemerintah Daerah DKI Jakarta "belum diimplementasikan". Keempat, impelementasi kebijakan Hari Bebas Kendaraan Bermotor (HBKB), sudah diimplementasikan dengan baik.

Dengan demikian dapat disimpulkan bahwa Pemerintah Daerah DKI Jakarta belum dapat mengimplementasikan kebijakan Peraturan Daerah DKI Jakarta Nomor 2 Tahun 2005 tentang Pengendalian Pencemaran Udara secara efektif dan efisien.

Rekomendasi didasarkan hasil evaluasi, pengamatan lapangan, opini yang diungkap responden serta bentuk-bentuk temuan lainnya selama melakukan penelitian, diajukan beberapa rekomendasi: (1) Hendaknya Pemerintah Daerah DKI Jakarta terus aktif melakukan sosialisasi kebijakan kepada masyarakat agar masyarakat paham isi kebijakan tersebut, melakukan pengawasan yang lebih intensif lagi, mengambil tindakan tegas, menjatuhgkan sanksi bila melanggar, demi pencapaian udara yang bersih di DKI Jakarta; serta melakukan evaluasi isi kebijakan 5 (lima) tahun sekali, apakah kebijakan perlu direvisi, (2) Hendaknya kepada institusi Pemerintah Daerah DKI Jakarta terkait dapat melakukan pemantauan, pendataan, dan pelaporan atas kegiatan pengendalian pencemaran udara secara 
IJEEM: Indonesian Journal of Environmental Education and Management, Volume 1 Nomor 1 Januari 2016

menyeluruh dan periodik untuk mendapatkan basis data dalam melaksanakan pengawasan dan monitoring, (3) Kiranya perlu pentaatan hukum dan peraturan dengan program rewards and punishment sebagai alat kontrol bagi pemilik kendaraan yang akan memperpanjang STNK, pemasangan stiker lulus uji emisi untuk mendapatkan perlakuan khusus, serta perlu adanya kebijakan memberikan penghargaan pemotongan pajak untuk kendaraan beremisi rendah agar menaikkan minat produsen kendaraan memproduksinya dan ketertarikan masyarakat membeli kendaraan beremisi rendah, (4) Kiranya saat ini karena bensin dan solar langka, mulai diterapkan penggunaan bahan bakar gas di Jakarta, karena ramah lingkungan dan perlu penerapan ecodriving untuk membuat dan perpanjangan Surat Izin Mengemudi (SIM), merupakan salah satu langkah efektif mengurangi kepemilikan kendaraan dan memperbaiki pola mengemudi sehingga menurunkan emisi kendaraan bermotor, serta perlu pemberian subsidi dalam rangka peningkatan mutu pelayanan angkutan umum agar menarik minat masyarakat untuk mengurangi penggunaan kendaraan pribadi.

\section{DAFTAR REFERENSI}

Dunn, William N. Public Policy Analysis: An Introduction. New Jersey: Pearson Education, 1999.

Haas, Peter J., dan J. Fred Springer. Applied Policy Research: Concepts and Cases. New York: Garland Publishing, 1998. 
IJEEM: Indonesian Journal of Environmental Education and Management, Volume 1 Nomor 1 Januari 2016

Majchrzak, Ann. Methods for Policy Research. California: Sage Publications, 1984.

Peraturan Daerah Provinsi DKI Jakarta Nomor 2 Tahun 2005 tentang Pengendalian Pencemaran Udara. 